\title{
Immunohistochemical localization of epidermal growth factor receptor (EGF-R) in normal and diseased newborn lung tissues*
}

\author{
G. Take, C. Ilgaz, D. Erdogan, C. Özogul
}

Department of Histology and Embryology, Gazi University, Faculty of Medicine, Ankara, Turkey

Received: April 25, 2001

Accepted: October 15, 2001

The distribution of EGF receptors (EGF-R) was examined in normal, hyaline membrane diseased and pneumonic newborn lung tissues by immunohistochemical methods under the light microscope. The PAP technique with polyclonal antibodies was performed to demonstrate the EGF receptor localisation in these tissues. Strong EGF-R reactivity was observed on bronchiolar epithelium and type I and type II alveolar cells in normal newborn loung tissues; whereas, poor reactivity was observed in alveolar macrophages. On the other hand, strong immunoreactivity was detected in type I alveolar cells and alveolar macrophages in hyaline membrane disease, but no reactivity was present in type II alveolar cells. The strongest immunoreactivity was observed in alveolar macrophages of newborn pneumonic lung tissues. In conclusion, the most meaningful form of reactivity was observed in normal newborn lung tissues of airway track and respiration area. This result is related with the maturation of the lungs after birth.

Keywords: epidermal growth factor receptor, immunohistochemistry, lung newborn

Epidermal Growth Factor (EGF) was first detected by Cohen on the sobmandibular glands of male mice in 1962 (1). It was completely purified by Sawage et al. in 1972 (2). EGF which is a $6 \mathrm{kDa}$ polypeptide, contains 53 amino acids. It increases mitotic activity in epithelial and mesothelial cells $(3,4,5,6,7,8)$.

* This study was presented in 4th National Histology and Embriology Congress, 1999

Correspondence should be addressed to

Gülner Take, Assc. Ph.D.

Gazi Üniversitesi Tip Fakültesi

Histoloji ve Embriyoloji AbD.

Ankara Besevler 06500 Türkiye

Phone: (+90) (312) 2141000/6942

Fax: (+90) (312) 2134338 
EGF makes its activity by binding to its specific receptor (EGF-R) on the cell surface which is a $170 \mathrm{kDa}$ protein, containing 1186 amino acids. This interaction activates the tyrosine kinase domain of the receptor which is localized at the cytoplasmic region. Consequently, series of aggregations and phosphorylation events occur in the cell. The resultant EGF and EGF-R complexes pass to the cytoplasm and fuse mainly with the lysosomes $(9,10,11)$.

EGF is effective in division and differentiation of the normal cells (6). Recent studies have been performed to prove the effect of EGF in the tissue development of fetal phase $(12,13)$. It has also been reported that EGF is effective in newborn pathological tissues. However, it is thought that EGF is not effective in newborn pathological tissues. This is attributed to the insufficient EGF levels or deficiency of EGF-R on the surface of type II undifferentiated alveolar cells in the organism.

The aim of this study is to show the distribution of EGF-R in normal newborn lung tissues, hyaline membrane diseased and pneumonic newborn lung tissues by immunohistochemistry. The tissues were examined under the light microscope and compared with each other.

\section{Materials and Methods}

Preparation of tissue samoles: In the study, lung tissues of male newborns who were born in the 38th week of pregnancy and died in the first 24-hour of life were used. Immediately after death. One $\mathrm{cm}^{3}$ volumed pieces were taken from distal, proximal and medial parts from each of the lungs and subsequently fixed in neutral formaline for 72 hours. Later they were examined by usual light microscope follow-up and embedded in parafine. Slices from these samples were stained by Hematoxylin - Eosin and examined and diagnosed by Department of Pathology, Faculty of Medicine, Gazi University. From normal (n:5), hyaline membrane diseased (n:5) and pneumonic (n:5) male newborn lung tissues were taken from the samples and cross-section $(4-5 \mu \mathrm{m})$ were placed on polilyzine covered slides. Each section of tissue blocks was deparaffinized with xylene and dehydrated.

Antibodies and staining procedure: Endogenous peroxidase activity was blocked in 3\% hydrogen peroxide (Fisher Scientific, Melrose Park. IL) for 10 minutes and they were incubated with saponin to help easy binding of primary antibody to antigenic areas. Epitopes were stabilized by application of serum blocking solution (Goat serum, Part\# A 1236-EA, Oncogene Science, Manhasset, New York, USA), for 20 minutes. Section were incubated with EGF-R rabbit polyclonal antibody Ab-4 $(100 \mu \mathrm{g} / \mathrm{ml}$, (Lot\#DO3571-1, Cat\#PC19-100UG, Oncogene Science, Manhasset, New York, USA) over night at $+4{ }^{\circ} \mathrm{C}$. The secondary antibody, $1 \%$ diluted biotin labeled anti rabbit total 
Ig (Biotinylated antibody, Part\#JA 1090-EA, Oncogene Science, Manhasset, New York, USA), was applited for 30 minutes at room temperature. A negative control was done by using normal rabbit IgG, (Lot\#DO2131-4, Cat\#NI01-100UG, Oncogene Science, Manhasset, New York, USA), instead of primary antibody. After washing with PBS, avidin-biotin-complex-peroxidase (ABC, Part\#JA 1236-EA, Oncogene Science, Manhasset, New York, USA) was applied to the slides. Diaminobenzidine (DAB, Oncogene Science, Manhasset, New York, USA), was used as chromogen. Afterwards, the slides were counterstained with hematoxylin for 1 minute, dehydrated in graded ethanol and mounted in a convectional medium (Mikroskopie Entellan\#740212765, Merck, Germany).

The intensity of the immunoperoxidase reaction was classified as follows: negative (-); when the cells were devoid of any detectable EGF-R expression; slightly positive (+); moderately positive (++); strongly positive $(+++)$. The entire case series were then evaluted by separating all the samples in two categories for EGF-R expression: negative (absence of reaction), and positive $(+,++,+++)$.

\section{Results}

The distributions of EGF-R in normal, hyaline membrane diseased and pneumonic newborn lung tissues are shown in Table I.

Table I

Distribution pattern of EGF receptors in different newborn lung tissues

\begin{tabular}{lccc}
\hline Affected region of lung & \multicolumn{3}{c}{ Groups } \\
\cline { 2 - 4 } & $\begin{array}{c}\text { Normal } \\
\text { newborn }\end{array}$ & $\begin{array}{c}\text { Hyaline membrane } \\
\text { disease }\end{array}$ & $\begin{array}{c}\text { Newborn } \\
\text { pneumonia }\end{array}$ \\
\hline Bronchiolar epithelium & $++^{* *}$ & ++ & $+++^{* *}$ \\
Bronchiolar nonnec. tissues & ++ & ++ & ++ \\
Type I alveolar cell & +++ & +++ & ++ \\
Type II alveolar cell & +++ & - & ++ \\
Alveolar machrophages & + & +++ & $+++^{*}$ \\
Interstitial connec. tissue & ++ & + & ++ \\
\hline
\end{tabular}

* Amout of cells are large in number

** Immunoreactivity is strong in apical cell membrane and in cytoplasm

Negative (-); when the cells were devoid of any detectable expression; slightly positive (+); moderately positive (++); strongly positive (+++) 


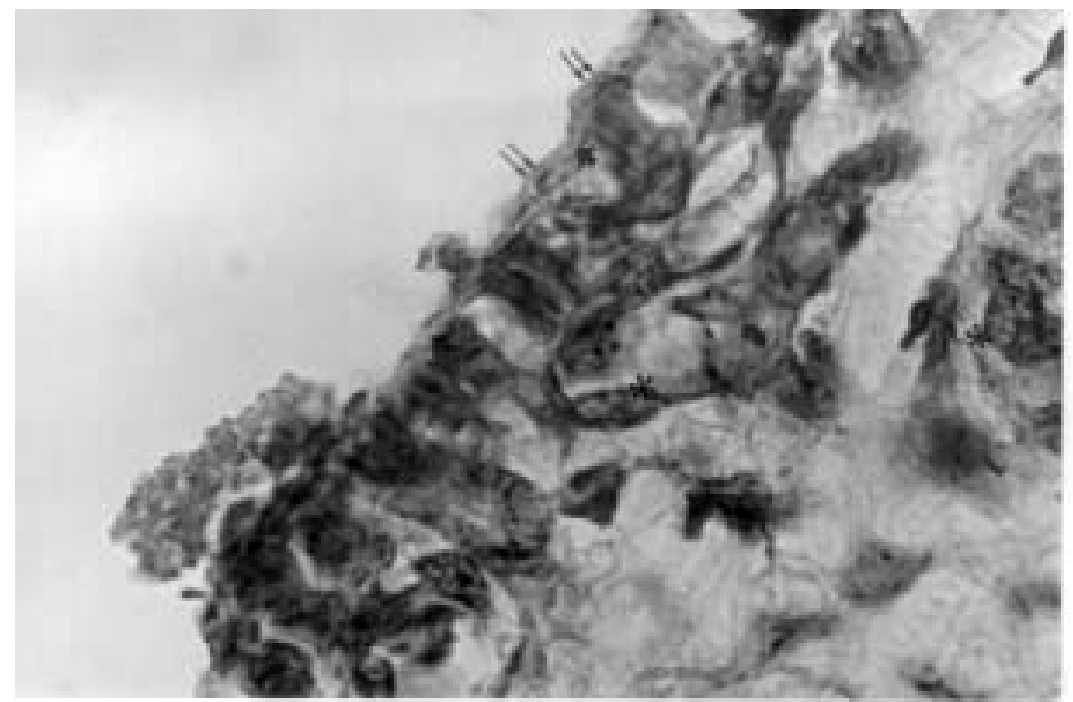

Fig. 1a. Normal newborn lung, apical cell membranes $(\uparrow \uparrow)$ and cytoplasms of bronchiole epithelium $(\rightarrow)$. Connective tissue $(*)$ (immunoperoxidase, Hematoxylin $\times 1000$ )

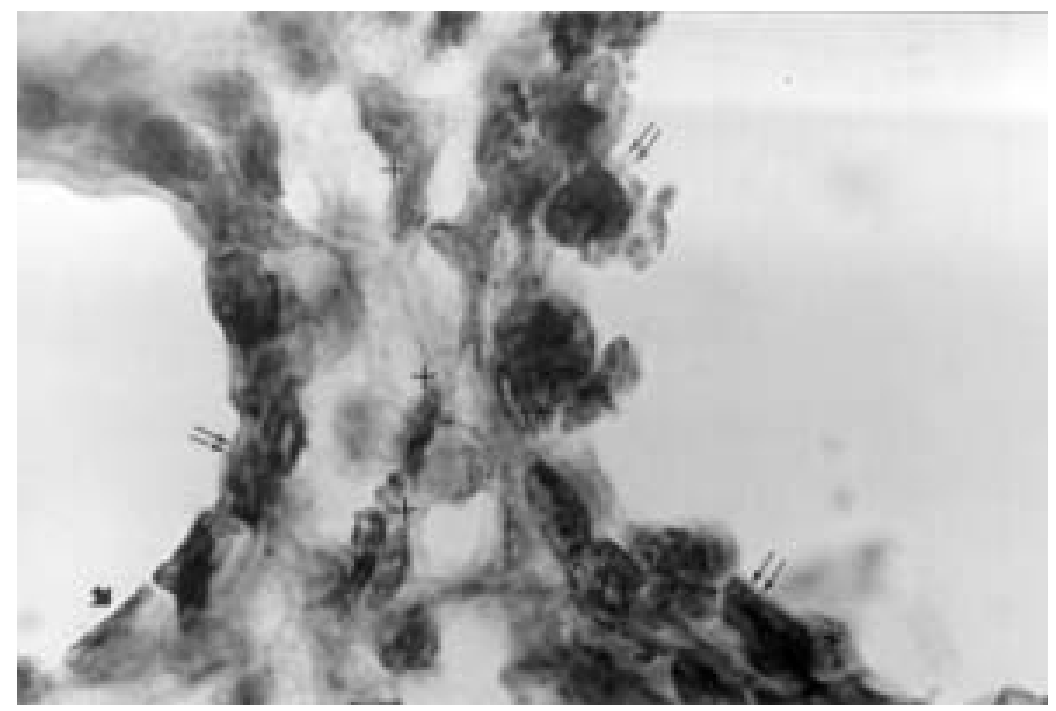

Fig. 1b. Normal newborn lung respiration area, types I and II alveolar cells ( $\uparrow$ ), type I alveolar cells membrane $(\rightarrow)$, type II cells cytoplasm $(*)$. Interstitial connective tissue $(+)$. (Immunoperoxidase, Hematoxylin $\times 1000$ ) 


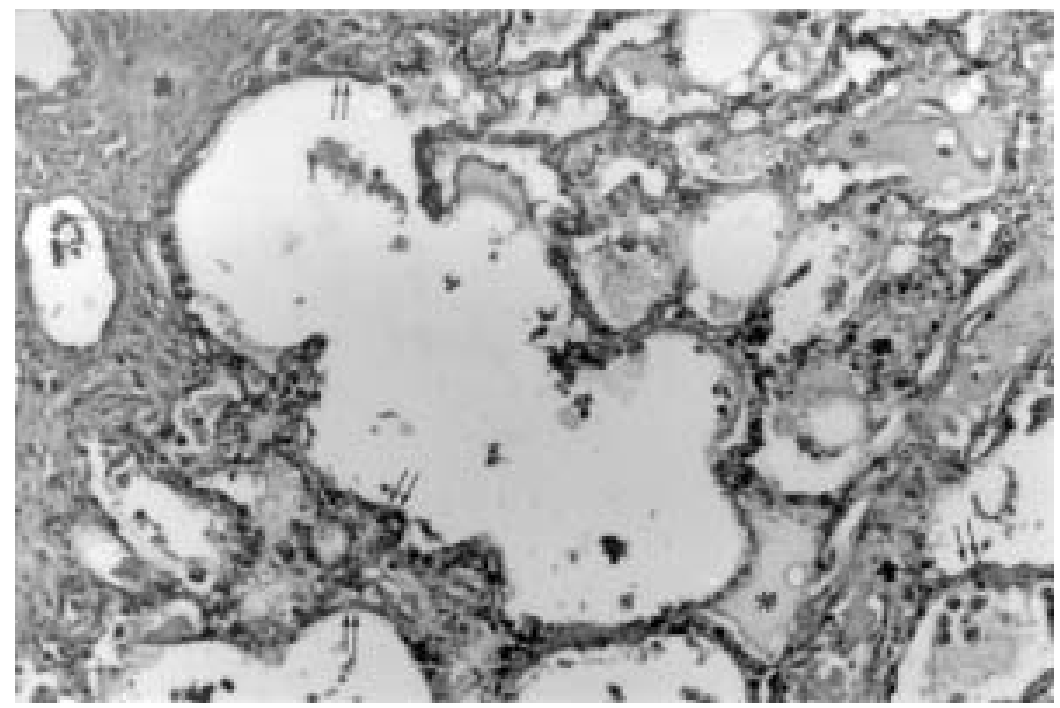

Fig. 2a. In lung tissue with hyaline membrane disease, lumens with edema fluid $(*)$. Membranous reactivity $(\uparrow \uparrow)$. Interstitial connective tissue $(\rightarrow)$. (Immunoperoxidase, Hematoxylin $\times 200$ )

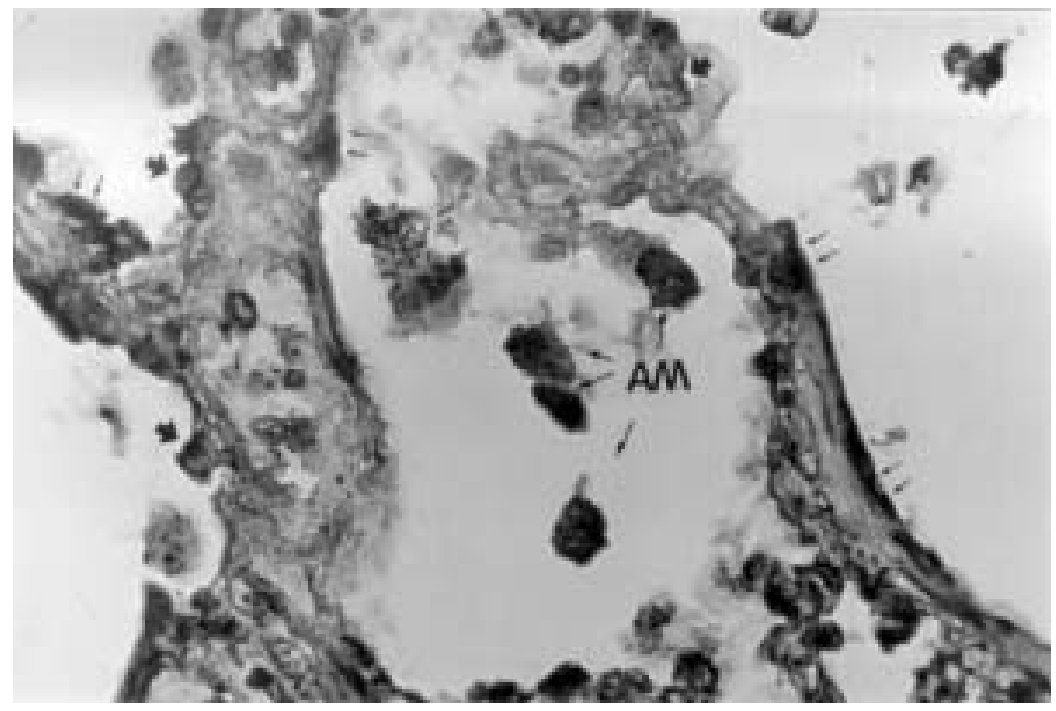

Fig. 2b. In the respiration area of hyaline membrane disease, type I alveolar cells $(\uparrow \uparrow)$, alveolar macrophages $(\mathrm{AM})$, type II alveolar cells $(\rightarrow)$. (Immunoperoxidase, Hematoxylin $\times 400$ ) 


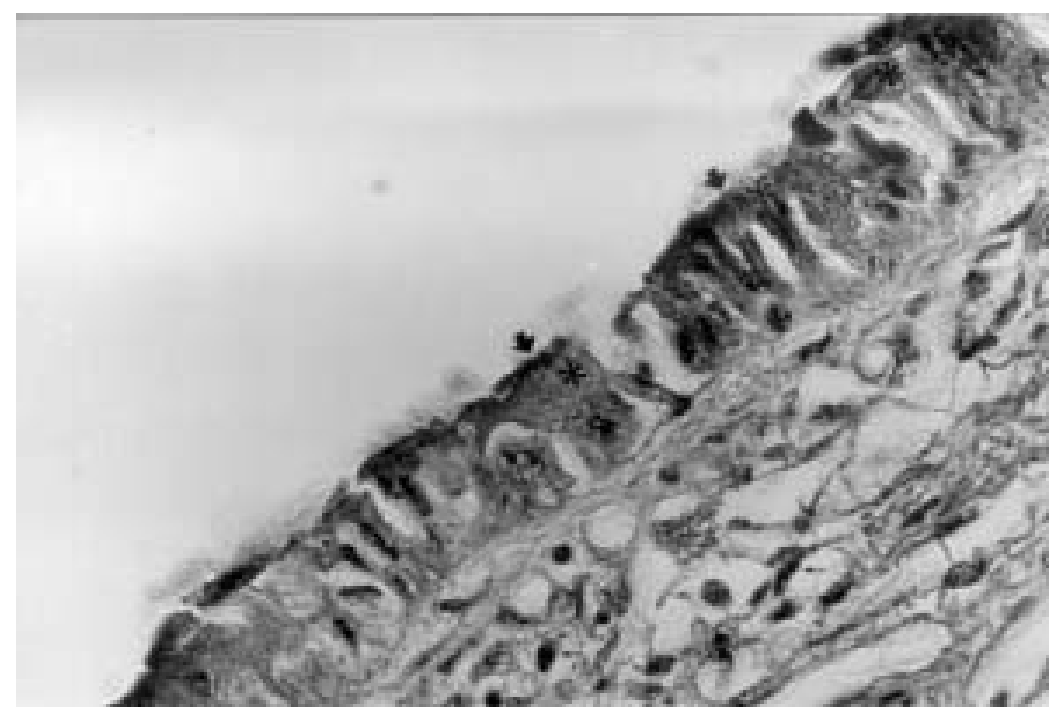

Fig. 3a. In the airways of pneumonic lung tissues, membrane $(\rightarrow)$, apical cytoplasm $(*)$, basal cytoplasm $(\uparrow \uparrow)$. Connective tissue $(\uparrow)$. (Immunoperoxidase, Hematoxylin $\times 400$ )

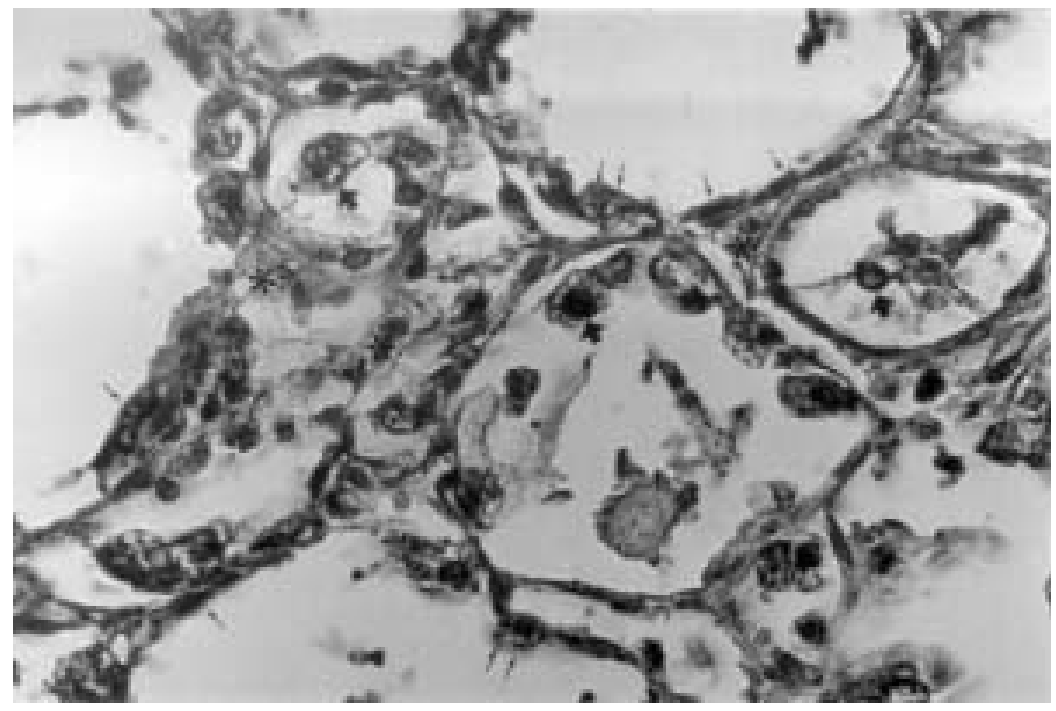

Fig. 3b. In respiration area of pneumonic lung tissue, type I alveolar cells ( $\uparrow$ ), type II alveolar cells ( $\uparrow$ ), alveolar machrophages $(\rightarrow)$. Interstitial tissue $(*)$. (Immunoperoxidase, Hematoxylin $\times 400$ ) 
EGF-R was observed in the parenchyma and stroma of normal newborn lung tissues. Moderate immunostaining was found in the apical cell membrane and the cytoplasm of bronchiolar cells. Fibroplasts and other cells of the connective tissue also had moderate immunoreaction (Fig. 1a). In the alveolus, generally a strong reactivity was observed in types I and II alveolar cells. Some of the type II alveolar cells showed immunoreaction only on their membrane but the others showed the staining both on their membrane and in the cytoplasm (Fig. 1b).

It was noticed that in hyaline membrane disease, bronchiolus reactivity was similar to the normal newborn lung tissues (data not shown). In respiration area, alveoli were filled with the edema fluid. There was also strong immunoreaction of the membrane in the whole alveoli. However, poor staining was present in interstitial connective tissue (Fig. 2a). In type I alveolar cells, strong immunoreactivity was found. Also, strong immunoreactivity was seen in alveolar macrophages when comprated to the normal tissues. Related to the pathogenicity of the disease, no immunoreactivity was observed in type II alveolar cells (Fig. 2b).

In the bronchiolus epithelium of the newborn pneumonic lung tissues, strong membrane and apical cytoplasmic staining were observed, whereas poor immunoreactivity was seen in basal cytoplasm. It was found that in the stroma, the fibroplasts and the other cells exhibited moderate reactivity (Fig. 3a). It was interesting to others had moderate immunoreactivity. The increase in the number of alveolar macrophages and their strong immunoreactivity was also evident (Fig. 3b). Moderate staining was observed in all cells of the interstitial connective tissues (Fig. 3b).

\section{Discussion}

EGF functions through binding to its specific receptors located on the cell surface (8). EGF-R has been shown in many tissues and body fluids $(4,5,6,7)$. Irma et al. have reported that the most EGF-R expression exists in skin and endometrium, but it is rare in lung and in intestinal cells (14).

Nexo et al. used radioactively labeled EGF in 13-week fetuses and found that EGF-R exists commonly in lung and kidney cells (15). A similar study was carried out by Warburton et al. in 1992 (16). They investigated the epigenetical function of EGF and observed strong reaction when exogenous EGF was introduced into the lung tissues in an 11-day embryonic mouse. They reported that EGF was effective in bronchus branches. In the same study, it was emphasized that EGF-R resulted in a widespread reaction in all lung tissues of the early embryonic stage. In the later periods, reactivity was observed mainly in parenchyma. 
Nielsen et al. reported that reactivity was found in the undifferentiated cells of air transport way, in mesothelial cells and also smooth muscle cells in the 10th week of fetal growth. After the 12th week, the reactivity was observed in all cells of airways. Moreover, alveolar cells like the other parts of the lung tissue showed strong immunoreaction after the 24th week of pregnancy (18).

In this study normal newborn lung tissues were examined in order to determine EGF-R expression. EGF-R reactivity was observed widely in all of the tissues. These results were similar to those reported before; immunoreaction in the airways was observed generaly in the apical cytoplasmic region and it was more evident on the cell membrane. In addition, the strong staining was observed in alveolar cells. These results show the continuation of the development and differentiation of alveoli after birth. Different from the Roucco's findings, we did not find smooth muscle reactivity.

Goetzman et al. found that surfactant and lecithin/sfingomyeline ratios were higher in the amnionic fluids of premature group compared to the control group. Thus, during the fetal period, EGF stimulates histological development of the lungs (19).

In the study, that they used rhesus monkey, when EGF was applied to a mother who was in her 3rd trimester of pregnancy, a significant change was observed in the structure of type II alveolar cells and also lamellar bodies were increased 3 times when comprated to the control groups (20). In the study of electron microscope with mice, when anti-EGF antiserum was given to a mother who was in her 3rd trimester of pregnancy, some structural differences in lamellar bodies of type II alveolar cells were determined and their numbers were decreased (21).

In the present study, in hyaline membrane disease, a strong immunoreactivity was observed in type I alveolar cells and in alveolar macrophages, whereas no reactivity was observed in type II alveolar cells. These findings seem to prove absence of the EGF-R in the type II alveolar cells accordance with the pathogeneticity of the disease.

EGF-R reactivity in newborn lung tissues with pneumonia was also studied. When respiration area was examined, the strong staining was found both in the cytoplasm and on the membrane of alveolar macrophages and also their number was increased. In this case, an inflammatory reaction is involved therefore the findings are accordance with the pathogenicity of the disease.

Generally, in this study, the most meaningful form of reactivity was observed in normal newborn lung tissues of aurways track and respiration area. This result was related woth the maturation of the lungs after birth. The particular finding that no EGF$\mathrm{R}$ immunoreactivity in type II alveolar cells were important and shows that these cells were not in function (i.e. not demonstrate stem cell charasteristic). A strong EGF-R reactivity of alveolar macrophages concluded in pneumonic newborn lung tissues may be caused by proliferation and increased cellular metabolic activity of these cells because of inflammatory reaction. 
We conclude that, for demonstrating the immunohistochemical expression of EGF-R could be the helper diagnosing method of cell pathology in the identification of pathologic tissues.

\section{REFERENCES}

1. Cohen S: Isolation of mouse submandibular gland protein elerating incisor eruption and eyelid opening in the newborn animal. J. Biol. Chem. 237, 1555-1562 (1962)

2. Sawage CR, Ingani T, Cohen S: The primary structure of EGF. J. Biol. Chem. 274, 7612-7621 (1972)

3. Cohen S: Epidermal growth factor. Bioscience Rep. 6, 1017-1028 (1986)

4. Crowford RJ, Penschow JD, Niall HD: Mouse prepro EGF synthesis by the kidney and other tissues. Nature 313, 228-231 (1985)

5. Damjanow I, Mildner B, Knowles BB: Immunohistochemical localization of the epidermal growth factor receptor in normal human tissues. Lab. Invest. 55, 588-592 (1986)

6. Feldman EJ, Aures D, Grossman M: Epidermal growth factor stimulates ornithin decarboxylase activity in the digestive tract of mouse. Proc. Soc. Exp. Biol. Med. 159, 400-409 (1978)

7. Görgün M, Özogul C, Erdogan D: The effects of epidermal growth factor to newborn mice. Gazi. Med. Jour. 5, 113-117 (1994)

8. Özogul C, Karaöz E, Erdogan D: Immunohistochemical localization of epidermal growth factor receptor in normal mouse tissues. Gazi. Med. Jour. 8, 105-109 (1997)

9. Cooper JA, Bowen PD, Raines E: Similar effects of platelet-derived growth factor and epidermal growth factor on the phosphorylation of tyrosin in cellular proteins. Cell. 31, 263-273 (1982)

10. Erbas D: Epidermal growth factor. Gazi. Med. Jour. 1, 30-34 (1990)

11. Sherrill JM, Kyte J: Activation of epidermal growth factor receptor by epidermal growth factor. Biochemistry 35, 5705-5718 (1996)

12. Gross I, Dynia DW, Rooney SA: Influence of EGF on fetal rat lung development in vitro. Pediatr. Res. 20, 473-477 (1986)

13. Sundell A, Serenius FS, Barthe P: The effect of EGF on fetal lamb lung maturation. Pediatr. Res. 9, 371-378 (1975)

14. Irma E, Palazzo G, Adams GP: Expression of mutated epidermal growth factor receptor by non-small cell lung carcinomas. Cancer Res. 53, 3217-3220 (1993)

15. Nexo E, Kryger-Baggesen N: The receptor for epidermal growth factor is present in human fetal kidney, liver and lung. Regul. Pept. 26, 1-8 (1993)

16. Warburton D, Seth R, Shum L: Epigenetic role of epidermal growth factor expression and signalling in embryonic mouse lung morphogenesis. Dev. Biol. 149, 123-133 (1992)

17. Nielsen HC, Martin A, Volpe MV: Growth factors control of growth and epithelial differentiation in embryonic lungs. Biochem. Mol. Med. 6, 38-48 (1997)

18. Ruocco S, Lallemand A, Tournier JM: Expression and localization of epidermal growth factor, transforming growth factor-alpha and localization of their common receptor in fetal human lung development. Pediatr. Res. 39, 448-455 (1996)

19. Goetzman BW, Read LC, Plopper CG: Prenatal exposure to epidermal growth factor attenuates respiratory distress syndrome in rhesus infants. Pediatr. Res. 35, 30-36 (1994)

20. Plopper CG, St George JA, Read LC: Acceleration of alveolar type II cell differentiation in fetal rhesus monkey lung by administration of EGF. Am. J. Physiol. 262, 313-321 (1999)

21. Yasui S, Nagai A, Ohira A: Effects of anti-mouse EGF antiserum on prenatal lung development in fetal mice. Pediatr. Pulmonol. 15, 251-256 (1993) 